proved to be a pyramidal shaped piece of brass about three $\mathrm{mm}$. high. The scleral flap was closed by means of the previously inserted suture and the conjunctiva replaced.

The post-operative period was satisfactory and the patient left hospital after a fortnight. On examination a month later the patient had a white eye with no sign of bulging in the area of the flap. There was some very fine pigment disturbance on the back of the cornea. Lens and fundus-no abnormalities. Vision with -0.75 cyl. axis $175^{\circ}-6 / 6$.

Many surgeons advise immediate X-ray of every perforating injury, whether or not a foreign body is visible. It is interesting to note that had this been done in this case it would have revealed the blunt end of the particle lying behind the iris. Removal through the cornea would not then have been attempted.

Complete success cannot be claimed for any operation of this , nature until the case has been observed over a long period. It is felt, however, that owing to the increased liability to intra-ocular injury by non-magnetic particles during war-time, it is worthy of note at present.

My thanks are due to Sir Richard Cruise and the Surgeons of the Royal Westminster Ophthalmic Hospital for permission to publish this case and to Mr. P. L. Allen for his assistance and advice.'

\title{
REFERENCES
}

1. CRUise, Sir Richard.-Trans. Ophthal. Soc, U.K., 1915.

2. BoRLeY and LEef.-Amer. Jl. Ophthal., Vol. XX, No. 12, December, 1937.

3. SPaETh, E. D.-Ji. Amer. Med. A ssoc., Vol. CXX, No. 9, October, 1942.

4. SAvin, L. H.-Hunterian Lecture, Royal College of Surgeons, 1943. (Pending publication).

\section{AN INTERESTING CASE OF RUPTURE OF THE CHOROID}

\author{
BY. \\ Captain Emanuel Rosen, M.C.
}

THE case reported by Humphrey Neame " Multiple Ruptures of the Choroid with Retention of Good Vision" in the Brit. Jl. Ophthal., p. 399, 1940, has come to my attention and it is for this reason that $I$ am submitting the following case:

J. S., aged 33 years, suffered an injury to his tight eye when he was chopping wood-he was struck. by an end over end flying piece of wood. Although there was severe damage to the eye, the patient does not recall having been attended by an oculist. He does not 
recall any further history except that he has had periodic refractive changes by an optometrist since the age of 17 years.

At present he complains of blurred vision for close work with duration of these symptoms approximately six months. Vision in the right eye is $20 / 25$ and in the left eye 20/70-1. The left eye disclosed'no abnormality other than a refractive error and was readily corrected to $20 / 20$ with -0.5 D.sph. -2.25 D.cyl. axis $25^{\circ}$ The pupil of the right eye was larger than that of the left and there was only partial response of iris to light since there was a break in the "collarette" and definite evidence of iris atrophy upon retroillumination. The pupil had an eccentric location nasally. When the pupil was dilated with homatropine a rupture of the zonule was visible nasally and the lens could be seen dislocated posteriorly in a very small degree. There was evidence of vitreous degenerationslit-lamp studies showing a break-down of the vitreous framework and a large "cord like mass" in the vitreous.

The fundus picture reveals the four ruptures of the choroid which so closely simulates the drawing shown in the case reported by Humphrey Neame: The picture, which shows four tears of the choroid discloses the two smaller ruptures situated very close to the

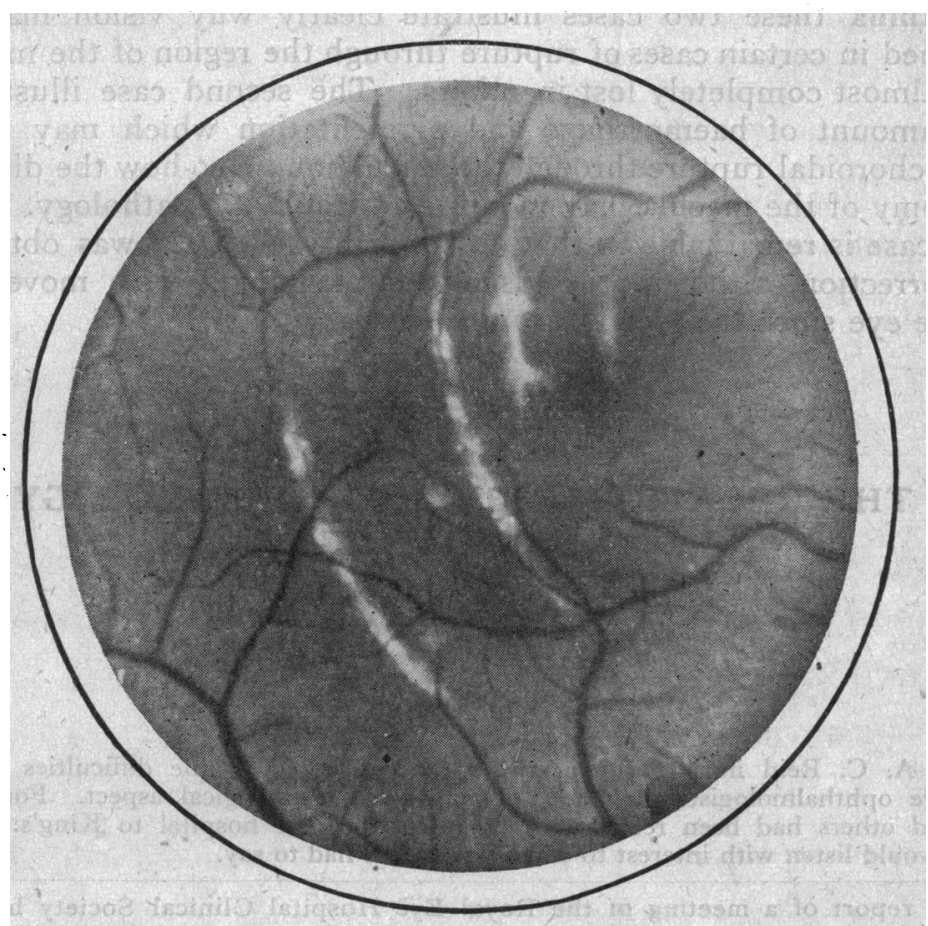

FIG. 1. 


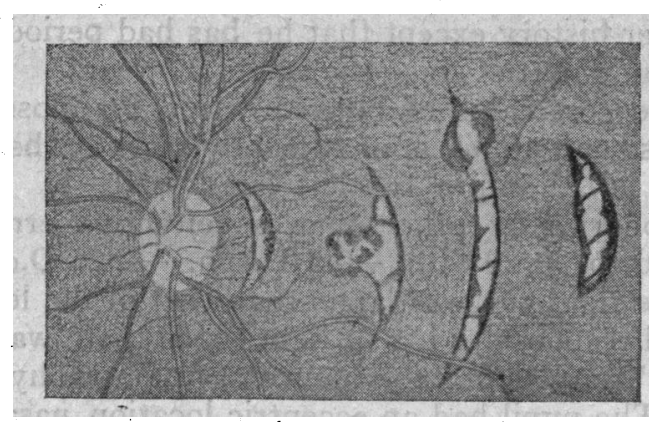

FIG. 2.

macula. : The second rupture which is shaped somewhat like the head of a spear seems to be quite close to the macula. The third and fourth ruptures are typical crescentic injuries.

'About the time I was preparing to report this case I saw a second case with four choroidal ruptures. The patient was a coloured soldier who injured his eye several years ago. His vision in this right eye is $8 / 200$. Since no fundus camera was available I attempted to make a fundus drawing of the condition which existed.

I think these two cases illustrate clearly why vision may be retained in certain cases of rupture through the region of the macula and almost completely lost in others. The second case illustrates the amount of haemorrhage and pigmentation which may occur with choroidal rupture through the macula and also how the distinct anatomy of the macula may modify the traumatic pathology. The first case is remarkable in that visual acuity of $20 / 20$ was obtained by correction, although the visual acuity changes with movement of the eye since the lens is not anchored.

\title{
THE RELATIONSHIP OF OPHTHALMOLOGY AND RHINOLOGY*
}

\section{BY}

\author{
V. E. NEGUS \\ LONDON
}

Dr. A. C. Reid in introducing the speaker referred to the difficulties of the average ophthalmologist when a case had an oto-rhinological aspect. For years he and others had been referring such cases from the hospital to King's. Now they would listen with interest to what Mr. Negus had to say.

- A report of a meeting of the Royal Eye Hospital Clinical Society held on September 24, 1943. 